\title{
Analysis of Electricity Billing System in Corporate Buildings in Lagos, Nigeria
}

\section{T.A Arimoro}

Department of Estate Management, Federal University of Technology, Akure. wudety@gmail.com

\section{A.K Oyetunji}

Department of Estate Management, University of Benin

Lancaster Environment Centre, Lancaster University United Kingdom

Corresponding author: abiodun.oyetunji@uniben.edu

\section{O.E Odugboye}

Department of Architecture, University of Benin

School of Architecture, Planning and Landscape, Newcastle University, U.K emmanuel.odugboye@uniben.edu

\begin{abstract}
Purpose: This research is set to the electricity billing system in AHCN Tower, Ikeja, Lagos State with a view to providing a sustainable and efficient electricity billing system to be adopted in the facilities management of multi-tenanted buildings.

Design/methodology/approach: Relevant data for the study were gathered through an interview conducted on the stakeholders responsible for the management of the property and the occupants. The collected data were analyzed using inferential statistics.

Findings/Discussion: The result revealed that the introduction of automated prepaid meters reduces the difficulties encountered in the manual system while apportioning electricity bills among the tenants.

Conclusion: The study, recommends that since information technology is now global, the stakeholders in facility management practice should collaborate to secure an application program that will serve for the management of commercial buildings.
\end{abstract}

Keywords: Automated, Billing system, Commercial property, Electricity, Facility Management, Lagos

\section{INTRODUCTION}

The management of commercial buildings requires expertise in facilities management. In line with the quest for efficiency and improved environment, the management of facilities installed 
in multi-tenanted commercial properties becomes a necessity. This is very essential as the building aesthetics is paramount to its value and potentialities. Therefore, the task of managing and administering service charge on a multi-tenanted property comes to regulate physical and functional obsolescence whilst enhancing the utility value of the service jointly benefitted by the tenants to bring it to an acceptable standard. According to Christudason (2004), multi-tenanted complexes are distinguished by three characteristics: individual ownership of a unit, shared ownership of common property, and collective membership in a corporate body that assumes responsibility for the management of the development. Buildings, specifically commercial buildings, account for a significant proportion of the overall electricity used globally.

Shared living spaces are a special case, whereby the problem of personal electricity apportionment is relaxed to an extent that the personnel typically occupy different rooms and hence room-level electricity apportionment is enough to achieve the desired results. Such room level electricity apportionment will also then allow for billing each occupant for their own electricity consumption, thus motivating electricity conservation behavior. This scenario of individual apportionment is important for increased transparency in the actual energy consumption of rooms in commercial buildings. Bedwell et al., (2014) revealed that a building user's electricity consumption is a socio-technical system, a function of workplace systems, equipment and culture which can be altered through interferences. Emerging technologies and understanding make it increasingly possible to deliver specific feedback where energy consumption data are apportioned to occupants, or to spaces and systems, to encourage efficiency and conservation. The increase in electricity consumption has been an ever-growing concern for the past several decades (Thakur et al., 2014). However, measuring the electricity usage of an individual, within a multi-occupant home, is very crucial as it requires monitoring at a much finer-grained level. It entails having the information about what the user is doing when he is doing it, where is he doing it and so on.

Accurate energy accounting is a difficult problem to solve using only a single smart meter. Increasing energy consumption of commercial buildings has motivated numerous energy tracking and monitoring systems in recent years. An area that is less explored in this domain is that of energy billing whereby total energy usage of a commercial building is disaggregated and accurately attributed to each of the occupants. The power supply is very crucial to every business operation. The failure of power supply in Nigeria in recent times has crippled many businesses within the country. In Nigeria, electricity consumers are often faced with the problems of inaccurate, irrational and delay in monthly billing due to the drawback in reading pattern and human errors (Adegboye et al., 2013). There is arbitrary and lack of transparency in the method used by energy provider to cost and assess the customer energy consumption. Such dark practices manifest through estimated billing systems and irregularity in metering. It is noted that the bill for any current month is prepared when the period has not ended, sometimes, in discriminatory charging due to loss of revenues incurred by distribution companies (Jain \& Bagree, 2011; Ofonyelu \& Eguabor, 2014). The use of a centralized meter servicing all tenants in the commercial properties has also not helped matters. Some tenants claim that others have more gadgets in their offices than they do and believe they should pay less. Occupants in these buildings typically occupy their individual spaces but the apportionment at the end of any given time does not yield their actual energy consumption, resulting in either excessive payment for the unit not consumed. Sometimes, the sum apportioned to each occupant may not cumulate up to the total charges for electricity in the building. Even if the property owner would want to do separate billing for each room, complex electrical infrastructure together with high metering costs makes it prohibitive. 
The time frame used to resolve such matters leads to delay in payments which have often led to disconnection of service to the property. This equally means the continuous running of the generator which results to pressure on diesel usage bearing in mind that it is quite expensive (Achoru, 2005). Thus, it is essential to have an efficient and effective system for such purposes via an electronic platform with consideration to proximity. This study seeks to answer questions on what factors influences the electricity billing system and of what effect does the electricity billing system has on the facility management.

\section{ELECTRICITY BILLING SYSTEM}

According to Makanjuola et al., (2015) energy meter is a device designed to quantify or measure the volume of electricity consumed at a given point in time by an electrically powered device, residence, commercial premises or an industrial complex. Typically, electricity meters are calibrated in billing units of kilowatt hour [kWh]. The electricity meters are read periodically to establish billing cycles and energy used during the cycle. The distribution companies use a monthly billing system in which the unit consumed in a previous month is paid in the succeeding month. In a typical bill, there are eight columns which contain: Descriptions, tariff code, read date, present reading, previous reading, multiplier, consumption and current charges. Under the descriptions columns there are always two rows which are energy charges and fixed charges. There is a number in the consumption column which is calculated by subtracting previous reading from the present reading. However, sometimes you can see a number with "E" by the side under the consumption column like 150E. This means that the consumption figure is not gotten from the meter reading but an estimate figure. The current charges obtained by multiplying the consumption figure with the energy multiplier charge which is dependent on the classification of the premises (i.e. R1, R2, R2SP, R2TP, C1SP) and so on. For the electricity billing, Current charge $=$ (consumption $\mathrm{x}$ energy multiplier charge) plus fixed charge plus VAT in Nigeria, where the fixed charge always includes the meter maintenance charge, and in R2SP premises, fixed charge is \#750.00 (Ofonyelu \& Eguabor, 2014; Ohajianya et al., 2014). There are three basic ways of charging electricity customers for the consumption of energy: Postpaid metering system, Estimated billing system and Prepaid billing system.

\subsection{POST-PAID AND ESTIMATED BILLING SYSTEMS}

Post-paid involves the payment of electricity bills after consumption by the customers; this has led to drastic increase in non-payment of bills by customers of the Power Holding Company of Nigeria (PHCN). While Estimated billing system is said to be analogous to fraud where consumers are mandated to pay far above what they consumed monthly. Most of the customers under this system are without meters and the residences are never visited to track the energy utilization over the period charged. Provision of meters to individual client may not totally eradicate this menace, however it is a good step forward to the means. PHCN bills consumers who were on direct connection (otherwise known as without meter) and those on post-paid meters with estimated bills. The main problem with billing by estimate had been the tendency to overcharge electricity users and provoke payment apathy.

In the past five years, over $80 \%$ of complaints received by NERC from consumers had been centered on issues of estimated metering, excessive tariffs with the metering methodology and poor metering infrastructure (Okafor, 2013). Defaults in payment of electricity bills by consumers arise a protest to perceived exploitation and negligence to complaints made to the PHCN authority. The problem with out-of-the-meter billing has been that its bill does not tally with the exact amount of energy consumed (Abubakar, 2009). The estimated bills are always dependent on the approximation of the PHCN. Under such instances, consumers who are 
already disconnected or had changed their metering plan continued to be billed with the old platform. The common feature of the estimated billings approach has been that the bills were always overpriced; amount charged sometimes remain constant over time even when electricity is rarely consumed and billing were sometimes discriminatory depending on the location of the consumer, the bill may merely require consumers to pay a specific monthly amount which was not dependent on the units of electricity supplied, consumed or the size of the building for which the bill was generated. Among all the classes of consumers, the bills of those that were on estimated tends to be higher compared to that of their counterparts whose consumption were read and metered.

About 6 million electricity consumers in Nigeria were noted to have no meters to monitor their electricity consumption monthly. This encourages estimated and fixed charges allocated to the consumers, but this results in defrauding acts by the consumers not paying anything out of the over blotted bills, the distribution companies incur great debt as a result, unable to pay the energy bought from the Generation Companies and invariably lack of enough power generation. The low power generated in Nigeria is being wasted by customers assisted by the default or the estimated/ postpaid billing systems adopted by distribution companies, they encourage power wastage and lead to breakdown of power distribution and transmission equipment (Ohajianya et al., 2014). These systems are known to be exploitative and destructive hence should be outlawed and replaced by prepaid. Estimated billing system affords opportunity for over pricing of energy consumption to the detriment of consumers. The distribution companies charge the utility by direct billings for the unmetered that are on direct connection, and postpaid for people with meters using estimated billing system.

Amadi (2013) observed that the issuance of estimated bills by the electricity distribution companies gives room to cheating the consumers. He opined that metering all electricity consumers would assist the customer to effectively monitor their electricity usage, as well as enable the distribution companies determine their revenue. The prepaid metering platform was aimed at addressing the asymmetries from both the sides of the consumers and the PHCN. While the general consensus of the consumers supports the introduction of the prepaid meters, the PHCN officials seemed averse to the development, owing to their preference for the distribution of the analogue than the prepaid meters.

\subsection{PRE-PAID METERING SYSTEM}

Prepayment metering is a well-established technology being introduced by more and more utility companies. According to Kettless (2004), prepayment metering system is a system where a customer pays for energy before using it which comprises a system master station (a computer that administers the whole system), a vending machine (where customers buy their electricity) and prepayment energy meters (or dispensers, which dispenses the electricity to the customer). This meter has an interface to the customer for managing the transfer of credit and to display the meter and credit status.

Prepayment method involves consumers to possess a credit in their electricity account before the usage of the service, when such credit is depleted, supply is remotely disconnected. Electricity prepaid billing system was first used in 1980s with the motives of providing electricity to the low-income earners of the community at affordable rates (Carolyne et al., 2013; McKinze, 2013). PHCN faced a daunting consumer debt profile as well as revenue collection difficulties, led to the introduction of pre-paid system in 2016 (Carolyne, et al., 2013). This step was believed to boost revenue collection. The act of making advance payment to energy service is gradually taken over, it is a new way and growing trend of charging electricity consumers in the developed world like US. Prepaid services connote that the customers pay for electricity in 
advance while their meters track the spending because of energy consumption and give the amount of energy remain in their account (LIHEAP, 2014).

\subsection{AHCN TOWER ELECTRICITY BILLING SYSTEM}

The Association of Housing Corporations of Nigeria (AHCN) Towers uses automated electricity billing system. The property makes use of Electricity Control Management Interface otherwise known with the acronym (ECMI). This is a window-based management system (Application Program) that is designed to compete with other existing management system and improves on their deficiencies. This is a system where an occupant pays for energy before using it which comprises a system master station (a computer that administers the whole system), a vending machine (where customers buy their electricity) and prepayment energy meters, (which dispenses the electricity to the customer). This meter has an interface to the customer for managing the transfer of credit and to display the meter and credit status. More importantly, in AHCN Towers there exist a Customer Sales Point (CSP) Operator responsible for the operation of the Consumer Sales Point Server, who with the aid of the information provided on the system by the Electricity Control Management Interface can sell and or make available tokens to the occupants on request within the premise. However, both energy from power holding company of Nigeria (PHCN) and the one from the premise generator are been purchased through this system.

The ECMI is an Executive Information System (EIS) that determines the consumed power per unit time and performs its computation based on the sale rate of power per unit time and other parameters. Advalorem (2009) revealed that the importance of power billing system cannot be over emphasized because its calculation reflects the exact power consumption for the prospective consumers, and in monitoring the billing details of the electricity consumers. The application provides an environment to maintain the consumer details starting from getting new connection, payments, access to performance information by the management (Seshanna et al., 2006). It functions on an Intranet network and Internet domain and ensure timely availability of status parameters. The ability to view the reports online ensures access to the report from PC terminal or devices VLAN and WAN network with internet connection. Customers can lodge complaint or deal with new connections just by logging into the system. The ECMI helps to measure and monitor the electricity consumed by occupants in the building and transmitting the measured reading between the consumer and utility. This system helps the Electricity Board to access all data regarding the consumed power in AHCN Tower. It also possesses the ability to synchronize the existing database with management system without any loss of data and keeps track of customer details against their substation(transformer). The system provides complete solution to both STS and ARM STS meters. Moreover, it incorporates a scratch card vending solution (ability to recharge prepaid meter via mobile phones).

\section{METHODOLOGY}

Alawusa, commonly known as Alausa is a principal district in Ikeja, the state capital of Lagos State. It is the seat of the Lagos State Secretariat and offices of the Governor and DeputyGovernor of Lagos State. Alawusa also has a vibrant and growing Central Business District with several multinational business concerns like Cadbury Nigeria Plc and many others having their offices located in the area. It also has many low-density residential estates like the Cornerstone Estate; MKO Abiola Gardens located within it. This is a descriptive survey research, aimed at analyzing the electricity billing system in AHCN properties in Lagos State. A design that minimizes bias and maximizes the reliability of data collection and analysis was employed. Interview was conducted on the occupants of the commercial properties while questionnaires were used to collect data. Both primary and secondary data were collected to gather reliable 
facts about the electricity billing system in the property. The target population for the study include:

i. Occupants of AHCN Tower in Alausa CBD, Ikeja Lagos; and

ii. The Facility manager involved in its management.

The total occupants in the property were sampled and they were forty-seven (47) occupants. Due to the small number of occupants, the total population was sampled. The questionnaire contained questions on the apportionment system used in the commercial properties. Both descriptive and inferential statistics were used in analyzing the data.

The dependent variable and its associated independent variables to be applied for the multiple regression analysis in the achieving of this research is outlined in the operationalization of variables section. Tables 1 showed the variables and its associated scale of measurements to be employed in achieving these objectives.

Table 1: Variables for Multiple Regression

\begin{tabular}{|c|c|c|}
\hline Definition of Variables & Variable Code & Measurement \\
\hline \multicolumn{3}{|c|}{ Dependent Variable } \\
\hline $\begin{array}{l}\text { Effect of ECMI on the facility } \\
\text { management }\end{array}$ & EFFECMI & $\begin{array}{l}\text { Highly significant effect (5), } \\
\text { Significant effect (4), Average } \\
\text { effect (3), Little effect (2), No } \\
\text { effect (1) }\end{array}$ \\
\hline \multicolumn{3}{|c|}{ Independent Variables } \\
\hline Age of prepaid meters & AOPREP & Actual in years \\
\hline Availability of skilled operator & AVSOPE & Yes (1), No (2) \\
\hline Availability of internet services & AVINTER & Yes (1), No (2) \\
\hline $\begin{array}{l}\text { Effectiveness of info. storage and } \\
\text { retrieval }\end{array}$ & EFINFOSTOR & $\begin{array}{l}\text { Highly effective (5), Effective (4), } \\
\text { Neutral (3), Less effective (2), } \\
\text { Ineffective (1) }\end{array}$ \\
\hline Effective response to issues & EFRESI & $\begin{array}{l}\text { Highly effective (5), Effective (4), } \\
\text { Neutral (3), Less effective (2), } \\
\text { Ineffective (1) }\end{array}$ \\
\hline $\begin{array}{l}\text { Level of ECMI application to } \\
\text { electricity supply }\end{array}$ & LECMIAPP & $\begin{array}{l}\text { Highly employed (5), Employed } \\
\text { (4), Neutral (3), Less employed } \\
\text { (2), Not employed (1) }\end{array}$ \\
\hline $\begin{array}{l}\text { Level of smartphone application } \\
\text { to recharge }\end{array}$ & LSMARTPHONES & $\begin{array}{l}\text { Highly employed (5), Employed } \\
\text { (4), Neutral (3), Less employed } \\
\text { (2), Not employed (1) }\end{array}$ \\
\hline $\begin{array}{l}\text { Networking of sales point to } \\
\text { office units }\end{array}$ & NETSALPOINT & Yes (1), No (2) \\
\hline Availability of constant electricity & AVALKELECT & Yes (1), No (2) \\
\hline $\begin{array}{l}\text { Effectiveness of generator \& } \\
\text { PHCN }\end{array}$ & EFELECCTGEN & $\begin{array}{l}\text { Highly effective (5), Effective (4), } \\
\text { Neutral (3), Less effective (2), } \\
\text { Ineffective (1) }\end{array}$ \\
\hline
\end{tabular}

Source: Author's compilation, 2018 


\section{RESULTS AND DISCUSSIONS}

Analysis of the factors influencing electricity billing system in AHCN Towers Table 2: KMO and Bartlett's Test of Sphericity

\begin{tabular}{lcc}
\hline \multicolumn{2}{c}{ Kaiser-Meyer-Olkin Measure of Sampling Adequacy } & .857 \\
& Approx. Chi-Square & 1179.058 \\
Bartlett's Test of Sphericity & Df & 136 \\
& Sig. & .000 \\
\hline
\end{tabular}

Source: Data Analysis, 2018

The Bartlett's test of Sphericity was used in the test for the appropriateness of the sample from the population and the suitability of factor analysis. It tests for the adequacy of the sample as a true representation of the population under study (Alese \& Owoyemi, 2004). The Bartlett's test in Table 2 shows a chi-square of 1179.058 and a significant level of 0.000 , which is an indication of the adequacy of the sample. The Kaiser-Meyer-Olkin (KMO) test is another measure of sample adequacy. It is an index for comparing magnitudes of the observed correlation coefficients between all pairs of variables. It is small when compared to the sum of the squared correlation coefficient. A KMO value of 1 represents a perfectly adequate sample. A KMO of O represents a perfectly inadequate sample. The KMO value in Table 2 is 0.857 , which shows that the sample is reasonably adequate.

Table 3: Component Matrix ${ }^{a}$

\begin{tabular}{lcc}
\hline & \multicolumn{2}{c}{ Component } \\
\cline { 2 - 3 } Factors & $\mathbf{1}$ & $\mathbf{2}$ \\
\hline Customer Sales Point Server & .927 & -.424 \\
Customer Sales Point operator & .843 & \\
Electricity charges & .937 & \\
Vending machine & .937 & \\
Facility manager & .867 & \\
Lack of expertise & .913 & \\
RESTR & .954 & \\
Pay before use & .880 & \\
Respond to complaint & .711 & .511 \\
Standalone sales point & .662 & \\
Corrupt practices & .829 & \\
Incompetent resident engineer & .600 & .453 \\
Poor health and safety & .875 & .765 \\
Manipulation of charges & .929 & $\mathbf{1 . 7 9 1}$ \\
Overbilling & .978 & 10.533 \\
Restriction to personal engineer & .538 & 78.599 \\
Delay & & 4.190 \\
\hline Eigen value & $\mathbf{1 1 . 5 7 1}$ & 24.646 \\
Percentage of variance explained & 68.066 & 78.599 \\
Cumulative \% of variance explained & 68.066 & \\
\hline Rotation Sums of Squared Loading & 9.172 & \\
Percentage of variance explained & 53.953 & \\
Cumulative \% of variance explained & 53.953 & \\
\hline
\end{tabular}

Rotation Method: Varimax with Kaiser Normalization

Rotation converged in 3 iterations

Extraction Method: Principal Component Analysis

Source: Data Analysis, 2018 
The criticality of the seventeen (17) identified factors from the literature was also explored using Factor Analysis. Factor analysis was used to assess the multivariate relationship among the factors influencing electricity billing system in AHCN Tower in Lagos State based on frequency of occurrence. The analysis was conducted using Principal Component Analysis (PCA) (extraction method) to determine possible cluster relationships of the factors influencing electricity billing system and Varimax with Kaiser Normalization (rotation method) to make factors easily interpretable. The number of factors to be retained was specified based on social science rule which state that only the variable with a loading equal to or greater than 0.4 in absolute terms and percentage of Variance greater than 1 should be considered meaningful and extracted for factor analysis. The result presented in Table 3 below was obtained based on this rule. All factor analysis produced two factor groupings with Eigen values of 1.79 to 11.57 while the variance cumulative percentage is $78.599 \%$ as shown in Table 3 above. Rotation converged in 3 iterations. The factor loadings in Table 3 shows that all the variables of factor 1 contribute $53.95 \%$ to electricity billing system, while customer sales point operator, delay in rectifying issues, incompetent resident engineer and restriction to personal engineer factors contribute $24.65 \%$ respectively. The two factors contribute a total of $78.60 \%$ while the remaining $21.40 \%$ is accounted for by extraneous factors which are unique to the variable and other variables outside the control of the research.

\section{EFFECT OF THE ELECTRICITY BILLING SYSTEM ON FACILITY MANAGEMENT PRACTICE}

The effects of AHCN electricity billing system were assessed on facility management practice, using multiple linear regression statistics. In this study, the dependent variable is effect of ECMI while the independent variables are age of prepaid meters $\left(X_{1}\right)$, availability of skilled operators $\left(X_{2}\right)$, availability of internet services $\left(X_{3}\right)$, effectiveness of information storage and retrieval $\left(X_{4}\right)$, effective response to issues (X5), level of ECMI application to electricity supply ( $\left.\mathrm{X}_{6}\right)$, use of smartphones for recharge $\left(X_{7}\right)$, networking of sales point to office units $\left(X_{8}\right)$, availability of constant electricity in the office complex (X9), effectiveness of combining both power from $\mathrm{PHCN}$ and generator (X10).

Table 4: Model Summary

\begin{tabular}{ccccc}
\hline Model & $\mathrm{R}$ & $\mathrm{R}$ Square & Adjusted R Square & $\begin{array}{c}\text { Std. Error of the } \\
\text { Estimate }\end{array}$ \\
\hline 1 & $.925^{\mathrm{a}}$ & .855 & .815 & .21748
\end{tabular}

Source: Data Analysis, 2018

The data in Table 4 showed the model summary of the regression statistics. The model summary shows that the coefficient of correlation $(R)$ is 0.925 , thus indicating a strong positive correlation between the dependent variable and the independent variables. This implies that an improvement in any of the independent variables will lead to a corresponding improvement on the effect of ECMI on facility management practice. The R square value of 0.855 indicates that the regression model explained about $86 \%$ of the total variation in ECMI (dependent variable) as accounted for by the independent variables under consideration. 
Table 5: ANOVA test for statistical significance

\begin{tabular}{ccccccc}
\hline Model & & Sum of Squares & df & Mean Square & F & Sig. \\
\hline \multirow{3}{*}{1} & Regression & 10.042 & 10 & 1.004 & 21.232 & $.000^{\mathrm{b}}$ \\
& Residual & 1.703 & 36 & .047 & & \\
& Total & 11.745 & 46 & & & \\
\hline
\end{tabular}

Source: Data Analysis, 2018

The ANOVA (Table 5) shows that the model is statistically significant since Sig. was $.000^{\mathrm{b}}$, for $\mathrm{f}$ $<0.05$. The test statistic F, calculated value is 21.232 , the degree of error is 36 , and degree of freedom is 10 at $\alpha$ is 0.05 and this gives a table value of 2.11. This reveals that the $\mathrm{F}$ calculated value is higher than the table value which implies that the ECMI is significant to AHCN facility management. The F-value of 21.232 is significant at 0.05 level. Since the co-efficient of determination is $(86 \%)$ and significant, the model is believed to be good and useful for predicting the effect of ECMI billing system on AHCN Tower in Alausa CBD, Ikeja Lagos.

Table 6: Beta coefficients of the variables

\begin{tabular}{|c|c|c|c|c|c|}
\hline \multirow[t]{3}{*}{ Model } & \multicolumn{2}{|c|}{ Unstandardized Coefficients } & \multirow{3}{*}{$\begin{array}{l}\text { Standardized } \\
\text { Coefficients } \\
\text { Beta }\end{array}$} & \multirow[t]{3}{*}{$\mathrm{t}$} & \multirow[t]{3}{*}{ Sig. } \\
\hline & & & & & \\
\hline & B & Std. Error & & & \\
\hline (Constant) & 3.325 & .676 & & 4.917 & .000 \\
\hline AOPrepaid & .039 & .051 & .071 & .757 & .454 \\
\hline AVSOPE & -.093 & .180 & -.091 & -.513 & .611 \\
\hline AVINTER & .055 & .187 & .055 & .294 & .771 \\
\hline EFINFOSTO & -.253 & .045 & -.729 & -5.644 & .000 \\
\hline EFRESPO & -.189 & .075 & -.528 & -2.504 & .017 \\
\hline LECMIAPP & -.461 & .159 & -.961 & -2.896 & .006 \\
\hline LSMARTPHONES & -.020 & .046 & -.039 & -.436 & .665 \\
\hline NETSALPOINT & -.228 & .165 & -.219 & -1.387 & .174 \\
\hline AVACONSTELECTRI & .537 & .229 & .491 & 2.341 & .025 \\
\hline EFELECCTGEN & .050 & .084 & .079 & .600 & .552 \\
\hline
\end{tabular}

Source: Data Analysis, 2018

The standardized beta coefficient compares the strength of the effect of each independent variable to the dependent variable. The standardized beta coefficient as shown in Table 6 enables a comparison of the contribution of each ECMI variable (to the effect on real estate practice) to be made. From the Table 6, it was revealed that the level of ECMI application to electricity supply (ignoring the negative sign) in facility management transactions made the strongest contribution to explaining the effect of ECMI on facility management practice in AHCN Tower. It had the highest beta coefficient (0.961). Also, the $p$-value (as seen in the last column of the Table) tell whether the contributions of the respective independent variables to the dependent variable are significant. The variables whose $p$-values were less than 0.05 implies 
such variables contributes significantly to ECMI effects on facility management practice in the study area.

\section{SUMMARY OF FINDINGS}

a. The research revealed that the electricity control management interface used in the study area has great impact facility management practice, hence it is crucial to our practice

b. The use of automated prepaid meters with application programs reduces the stress accumulated by resident facility managers.

c. Disputes that often arise over apportionment of electricity charges was eliminated from the commercial property

d. Transparency exist in the electricity billing system of the study area.

e. The use of the application program avails the occupants the opportunity to purchase token at any time when the purchasing power is available without any constraints.

\section{CONCLUSION AND RECOMMENDATIONS}

Prospective office space clientele in recent times source for well-organized facility management properties to avoid unnecessary disputes. The electricity billing system overtime has had its ugly effect on both the facility management firms and occupant of various commercial properties in different forms which has resulted into different arbitration and court cases. In this sense, application program should be introduced to electricity billing system in multi tenanted buildings to effectively carryout their responsibility in the management of these properties. This research examined electricity billing system in commercial properties, using AHCN Tower, Alausa CBD, Ikeja as a case study. Regardless of the commercial property been considered, it is of utmost importance to identify the fact that the electricity billing system has great influence on facility management practice. Subsequently, with the advent of information technology in recent times, it is important that facility management firms should give room for result driven system to averts the norms of apportionment system in electricity billings. The following recommendations are made:

a. Facility management firms should endeavor to introduce the use of automated prepaid meter with application program to their commercial properties to minimize disputes that arises from the apportionment of electricity bills.

b. Facility managers should be transparent in all their dealings.

c. Stakeholders in the facility management should collaborate to procure an application program that will suit commercial properties.

\section{REFERENCES}

Abubakar, S. (2009). Design and construction of a computer based power billing system. Published dissertation, Federal University of Technology, Minna, Niger State, Nigeria. Ahmadu Bello Univeristy Journal of Technology, 13(1): 39-46.

Achoru, A. M. (2005). The problems/possible solutions of managing a high rise multi-tenanted office complex in Abuja metropolis. International Journal of Environmental Sciences, 5(5):1043-1051 
Adegboye, A., Ayeni, A. G., Alawode, J. A., \& Azeta, I. V. (2013). Design and implementation of an enhanced power billing system for electricity consumers in Nigeria. Afr J. of Comp $\mathcal{E}$ ICTs. African Journal of Computing \& ICT. 6(1):49-58.

Advalorem, U. (2009). Utility billing software: Energy billing system. <" http://www.avrub.com/contact.htm16" $>$ on the $16^{\text {th }}$ August, 2018.

Alese, B.K. \& Owoyemi, S.O. (2004). Factor analytic approach to internet usage in South Western Nigeria. Journal of Information Technology Impact, 4(3):171-188.

Amadi, S. (2013). FG cautions new power firms owners against crazy bills. http://www.nigeriancurrent.com/business-news/item/4915-fg-cautions-new-power-firmsowners-against-crazy-bills.html [Accessed 23/10/2018].

Bedwell, B., Leygue, C., Goulden, M., McAuley, D., James Colley, F. e., Banks, N., \& Spence, A. (2014). Apportioning energy consumption in the workplace: A review of issues in using metering data to motivate staff to save energy. Technology Analysis \& Strategic Management. 26(10):1196-1211.

Carolyne, N., Nyanamba, S., \& Nyangweso, G. (2013). An assessment of the effect of prepaid service transition in electricity bill payment on KP customers, A survey of Kenya Power, West Kenya Kisumu. American International Journal of Contemporary Research. 3(9):123-134.

Christudason, A. (2004). Common property in strata titled development in Singapore. Journal of Property Management. 22(1):14-28.

Jain, A., \& Bagree, M. A. (2011). Prepaid meter using mobile communication. International Journal of Engineering, Science and Technology. 3(3):160-166.

Kettless, P.M. (2004). Prepayment metering systems for the low-income group. London: PRI Ltd.

LIHEAP. (2014.). Prepaid utility service. Low-Income customers and LIHEAP; Clearing House Report.

Makanjuola, N., Shoewu, O., Akinyemi, L., \& Ajose, Y. (2015). Investigating the problems of prepaid metering systems in Nigeria. The Pacific Journal of Science and Technology. 16(2):2230.

McKinze, M. (2013). Prepayment meters and energy efficiency in indigenous households. A report for the Bush-light Centre for Appropriate Technology.

Ofonyelu, C., \& Eguabor, R. (2014). Metered and unmetered billing: How asymmetric are the Phon bills? Journal of Social Economics Research. 1(5):97-107

Ohajianya, O. E., Abumere, I. O., Owate, E., \& Osarolube, A. C. (2014). Erratic power supply in Nigeria: Causes and solutions. International Journal of Engineering, 3(7):23-32.

Okafor, C. (2013). Metering accounts for $80 \%$ of consumer complaints. Thisday. [Accessed 29 October 2013].

Pacific., U. N. (2013). Promotion of energy efficiency in industry and financing of investment.

Seshanna, P., Nashtara, I., \& Sajeed, A. (2006). Automated industrial load measurement system. AU J.T. , 10(1):23-8.

Thakur, S., Saha, M., Singh, A., \& Agarwal, Y. (2014). WattShare: Detailed energy apportionment in shared living spaces within commercial buildings. BuildSys'14, November 5-6, Memphis, TN, USA. 